\title{
Suppression of pain by exposure of acupuncture points to polarized light
}

\author{
Yuri P Limansky DSci, Zinaida A Tamarova PhD, Sergiy A Gulyar DSci
}

\begin{abstract}
YP Limansky, ZA Tamarova, SA Gulyar. Suppression of pain by exposure of acupuncture points to polarized light. Pain Res Manage 2006;11(1):49-57.
\end{abstract}

BACKGROUND: According to clinical studies, the stimulation of acupuncture points (APs) by a variety of methods (eg, needles, pressure, etc) is an effective method for the treatment of many pain syndromes. However, no experimental proof exists showing that the exposure of APs to low-intensity incoherent polarized (P) light evokes an analgesic affect.

OBJECTIVES: The authors' previous work, using mice, shows that the exposure of APs to low-intensity microwaves effectively decreases pain. The purpose of the present study was to determine whether exposure of APs to low-intensity incoherent P light evokes a statistically significant reduction in pain.

METHODS: The effects of $\mathrm{P}$ light on behavioural responses to acute and tonic pain were tested in mice. The threshold of vocalization during electrical stimulation of the foot (acute pain) was measured before and after exposure of AP E-36 to P light. The duration of licking the formalin-injected foot (tonic pain) was investigated in control mice and mice exposed to P light on APs E-36, V-56 and V-60 or on skin that did not contain analgesic APs.

RESULTS: Exposure of APs to P light evoked a statistically significant increase in pain threshold by $34.2 \%$ to $59.1 \%$, and shortened the licking time by $32.3 \%$ to $50 \%$ in mice. The most effective AP was E-36 in both the painful foot and the normal foot. After $2 \mathrm{~min}, 6 \mathrm{~min}$ and 10 min of P light exposure, analgesia was 7.6\%, 30.9\% and 50\%, respectively. The exposure to $\mathrm{P}$ light on skin that did not contain analgesic APs did not evoke significant effect.

CONCLUSIONS: The results show the efficacy of pain suppression by exposure of antinociceptive APs to P light.

Key Words: Acupuncture points; Acute pain; Analgesia; Pain and nonpain behavioural responses; Polarized light; Tonic pain

$\mathrm{P}$ hoto- or light therapy, which uses electromagnetic fields $(E M F s)$ in the optical ranges with different physical properties, has been known for its curative effects since ancient times. It is widely used to treat various diseases, including pain syndromes (1-4). The curative effect of light depends mainly on frequency, EMF voltage and duration of exposure $(5-8)$. Different authors rate the efficacy of phototherapy as high $(1)$, moderate $(3,4)$ or low $(2)$. Such contradictory data may arise from the subjectivity of pain estimation by patients as well as the impossibility of quantitative determination of pain intensity before and after treatment. The difference in treatment methods may be another reason for such contradictory data.

Dominique Arago discovered chromatic polarization of light in 1811. Only in the 1980s, however, did phototherapy

\section{La suppression de la douleur par l'exposition des points d'acupuncture à une lumière polarisée}

\begin{abstract}
HISTORIQUE : D'après des études cliniques, la stimulation des points d'acupuncture (PA) par diverses méthodes (p. ex., aiguilles, pression, etc.) représente un mode de traitement efficace de nombreux syndromes de douleur. Cependant, il n'existe aucune preuve expérimentale pour démontrer que l'exposition des $\mathrm{PA}$ à une lumière polarisée $(\mathrm{P})$ incohérente de faible intensité évoque un effet analgésique.

OBJECTIFS : Le travail précédent de l'auteur, effectué sur des souris, révèle que l'exposition des $\mathrm{PA}$ à des micro-ondes de faible intensité réduit la douleur avec efficacité. La présente étude visait à déterminer si l'exposition des $\mathrm{PA}$ à une lumière $\mathrm{P}$ incohérente de faible intensité évoque une réduction de la douleur significative d'un point de vue statistique.
\end{abstract}

MÉTHODOLOGIE : Les effets de la lumière P sur la réponse comportementale à la douleur aiguë et tonique ont fait l'objet d'essais sur des souris. Le seuil de vocalisation pendant la stimulation électrique du pied (douleur aiguë) était mesuré avant et après l'exposition du PA E-36 à la lumière P. La durée du léchage du pied injecté de formaldéhyde (douleur tonique) a été calculée chez des souris témoins et des souris exposées à la lumière P aux PA E-36, V-56 et V-60 ou sur la peau sans PA analgésique. RÉSULTATS : L'exposition des PA à la lumière $\mathrm{P}$ évoquait une augmentation statistiquement significative du seuil de douleur de $34,2 \%$ à $59,1 \%$ et réduisait la durée de léchage de $32,3 \%$ à $50 \%$ chez les souris. Le PA E-36 était le plus efficace, tant sur le pied douloureux que sur le pied normal. Après une exposition à la lumière $\mathrm{P}$ de 2 minutes, 6 minutes et 10 minutes, l'analgésie était de 7,6\%, de 30,9\% et de $50 \%$, respectivement. L'exposition à la douleur $\mathrm{P}$ sur la peau qui ne contenait pas de PA analgésiques n'évoquait aucun effet significatif.

CONCLUSIONS : Les résultats démontrent l'efficacité de la suppression de la douleur par l'exposition de PA antinociceptifs à la lumière P. 
All animals have APs connected by meridians, the topography, structure and functional properties of which coincide with similar systems in humans (11). Because of this, experiments on animals have increased the understanding of the mechanisms of the medical action of acupuncture (12-14). Experimental studies on animals that would provide an objective, quantitative assessment of the antinociceptive effect of low-intensity P light on APs, however, are practically nonexistent.

The purpose of the present study was to determine whether exposure of APs to low-intensity P light evoked a statistically significant reduction of pain. The effects of $\mathrm{P}$ light on acute and tonic pain in mice, using a vocalization test on an electrode floor and the formalin test, respectively, were tested. The AP areas exposed to P light were E-36, V-56 and V-60. E-36 is one of the basic APs, and renders fortifying and analgesic action on all organisms. APs V-60 and V-56 are used for treatment of pain in the lower extremities (15).

\section{MATERIALS AND METHODS}

\section{Animals}

Experiments were conducted on outbred, adult male, albino mice weighing $28 \mathrm{~g}$ to $33 \mathrm{~g}$. The mice were maintained in a vivarium with a controlled temperature $\left(20 \pm 1^{\circ} \mathrm{C}\right)$ and a $12 \mathrm{~h}$ light and dark cycle (lights on at 08:00); they also had free access to food and water. All experiments were performed from October 2003 through January 2004. The mice were brought to the test room three days before testing and individually housed in plastic cages $(36 \mathrm{~cm} \times 24 \mathrm{~cm} \times 15 \mathrm{~cm}$ ) with free access to food and water. Each animal was used in only one experiment and then received a lethal dose of urethane (intraperitoneally). Two methods were used: experiments with the formalin test were carried out between 10:00 and 12:00; and experiments with acute pain were carried out between 10:00 and 14:00. All experiments were conducted in accordance with the ethical guidelines recommended by the International Association for the Study of Pain for experimental pain in conscious animals.

\section{Exposure to $\mathrm{P}$ light}

A Bioptron Compact (Bioptron AG, Switzerland) was used as a light source. This device produced linearly P, polychromatic, incoherent, low-energy $\left(40 \mathrm{~mW} / \mathrm{cm}^{2}\right)$ light with wavelengths of $480 \mathrm{~nm}$ to $3400 \mathrm{~nm}$. The opaque nozzle created a beam $5 \mathrm{~mm}$ in diameter. The light filter was held $5 \mathrm{~cm}$ from the surface of the skin, and the duration of $\mathrm{P}$ light exposure was limited to $2 \mathrm{~min}$, $6 \mathrm{~min}$ or $10 \mathrm{~min}$. Measurements of skin temperature in the P light zone of action were taken by the precision contact microthermistor during the $10 \mathrm{~min} \mathrm{P}$ light session. The surface of the optical filter was parallel to the surface of the skin, and the distance from the skin to the filter was the same as in real experiments $(5 \mathrm{~cm})$. It was established that the increase in skin temperature at $10 \mathrm{~min}$ was approximately $1^{\circ} \mathrm{C}$ and the maximum temperature on the surface of the skin was $37.1^{\circ} \mathrm{C}$.

During $\mathrm{P}$ light exposure, the mice had to be restrained so that the beam remained focused on the AP. Mice were placed in narrow plastic cages with a hole for the left, the right or both hind limbs. The cage was fixed to a tripod with a special clamp, and the researcher carefully restrained the left hind limb during light exposure. In experiments with $2 \mathrm{~min}$ or $6 \mathrm{~min}$ of $\mathrm{P}$ light exposure, the animals remained in the cage for $10 \mathrm{~min}$ after the light was switched off. All mice were treated as above, control animals were restrained for the same $10 \mathrm{~min}$ period as the experimental animals but without P light exposure. Only one control group was used for comparison with each experimental group because all animals spent the same amount of time in the movement-restricting chambers.

\section{Experimental model of acute pain}

Twenty mice were randomly assigned to one of two groups of 10 : the experimental group received a single 10 min exposure of AP E-36 to P light; and the control group received a 10 min session without P light.

Acute pain was induced in all 20 mice by electrical stimulation of the skin on the feet. A mouse was placed on a conductive platform and covered by a transparent plastic box $(15 \mathrm{~cm} \times 10 \mathrm{~cm}$ $\times 5 \mathrm{~cm}$ ) with air holes, which did not limit the animals' movements but prevented them from jumping off of the platform. Pain threshold (in V) in the mice was recorded by progressively increasing the electrical stimulation to induce vocalization. A device that provided a smooth increase in voltage with a constant speed $(10 \mathrm{~V} / \mathrm{s})$ was used to standardize the experimental conditions. The voltage was limited to $100 \mathrm{~V}$. The sound reaction latency was between $3 \mathrm{~s}$ and $10 \mathrm{~s}$. Nine pain threshold values were determined for every mouse, three before exposure and six after exposure of AP E-36 to P light (experimental group) or imitation of $\mathrm{P}$ light (control group). Each of the nine values was calculated by taking the mean of three measurements, taken at $30 \mathrm{~s}$ intervals, every $30 \mathrm{~min}$.

\section{Formalin test}

The tonic pain area was produced by injecting formalin into the hind foot of a mouse. The formalin test is a classic model of the tonic chemogenic pain test $(16,17)$, which is widely used around the world. Licking of the injected foot is a typical behavioural response (BR) to pain.

Eight groups of mice (10 per group) received subcutaneous injections $(10 \mu \mathrm{l} / 10 \mathrm{~g}$ of weight) of $5 \%$ formalin solution (dissolved in $0.9 \%$ sodium chloride $(\mathrm{NaCl})$ solution) into the plantar surface of the left hind foot. A ninth group $(n=10)$ was injected with $0.9 \%$ solution of $\mathrm{NaCl}(10 \mu \mathrm{l} / 10 \mathrm{~g})$ in the same location. All injections were performed with a 26-gauge microsyringe while the mouse was in a movement-restricting chamber. The duration of licking the painful foot was used to evaluate the BR to pain. One of eight groups of mice that received the formalin was the control group (no P light treatment); the seven experimental groups were exposed to different durations of $\mathrm{P}$ light, in different locations. The duration of the BR in the control group was compared with each experimental group. The group that received $\mathrm{NaCl}$ only was not exposed to P light; this group was compared with the groups that received the formalin solution (dissolved in $0.9 \% \mathrm{NaCl}$ ).

Just after formalin injection, every experimental animal was exposed to P light on an area of skin that contained either an analgesic AP or no analgesic AP. The areas and durations of exposure to P light were: AP E-36 of the left hind foot ( $2 \mathrm{~min}, 6 \mathrm{~min}$ and $10 \mathrm{~min}) ; \mathrm{AP} \mathrm{E}-36$ of the right foot $(10 \mathrm{~min})$; both APs E-36 (on the left and right feet) simultaneously (10 min); AP V-60 of the left hind foot (10 min); AP V-56 of the left hind foot $(10 \mathrm{~min})$; and the skin of the medial surface of the left hind limb hip, an area where no specific analgesic APs have been detected $(10 \mathrm{~min})$. After finishing the P light session (for the experimental animals) or imitation session (for the control animals), the mouse was placed in its cage, and the BR to pain - licking of the injected foot was observed for $60 \mathrm{~min}$. Nonpain BRs, such as eating, sleeping, running and washing (licking of all body parts except the injected 
A

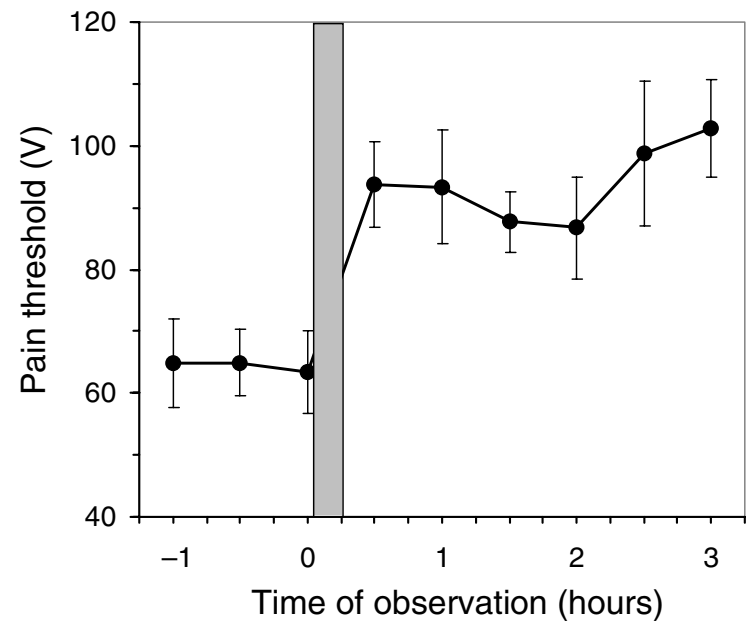

$\mathrm{B}$

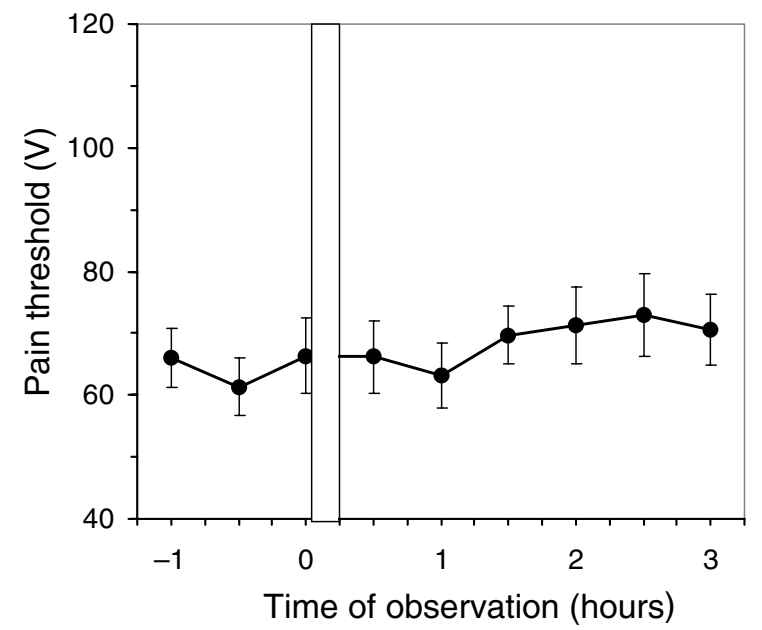

Figure 1) The mean ( \pm SEM) threshold of vocalization from the electrical stimulation of feet for two groups of mice with (A) and without (B) exposure of acupuncture point E-36 to polarized light. The period when the mice were in the partial immobilization chamber is indicated with rectangles: gray for mice who received the light therapy sessions (A) and white for mice in the control group (B)

foot), were also noted in all animals during this 60 min period. A computer program permitted the recording of all five BRs and calculated the duration of each for any stretch of time (after finishing the experiment).

\section{Data analysis}

In the acute pain experiments, every mouses' vocalization threshold was measured three times (at $30 \mathrm{~s}$ intervals); the mean value was then calculated as the pain threshold for the animal. These data were used to determine the mean pain threshold value in each group $(n=10)$.

In the tonic pain experiments, the onset and end of each licking cycle and each nonpain BR were recorded. Plots of the duration for all BRs, at $10 \mathrm{~min}$ intervals, and for the $60 \mathrm{~min}$ observation period, were constructed.

The mean and standard error were calculated for each treatment group, and significant differences among the groups were determined with one-way nonparametric ANOVA followed by a Student's $t$ test. A $\mathrm{P}<0.05$ was considered significant.

\section{RESULTS}

The effect of AP P light treatment on pain threshold in mice The mean threshold of vocalization from the electrical stimulation of the feet, for the experimental group of mice before P light treatment, generally fell within the range of $60 \mathrm{~V}$ to $70 \mathrm{~V}$. After a 10 min exposure of AP E-36 to P light, pain thresholds increased to $85 \mathrm{~V}$ to $100 \mathrm{~V}$, indicating a decrease in sensitivity to pain (Figure 1A). Thirty minutes after the start of an AP exposure to $\mathrm{P}$ light, the mices' average pain threshold had increased by $45 \%$ compared with the baseline value. These differences were statistically significant $(\mathrm{P}<0.001)$, and the effect was prolonged. Two hours after the start of light application on AP E-36, the mices' average pain threshold was still up by $34.2 \%(\mathrm{P}<0.01)$, and after $3 \mathrm{~h}$ it was $59.1 \%$ higher $(\mathrm{P}<0.001)$ than before $\mathrm{P}$ light treatment.

The observed decrease in sensitivity to pain is not a consequence of the animals' partial immobilization during AP exposure to $\mathrm{P}$ light. Controlled experiments where mice were exposed to a similar partial limitation of motor activity but not
P light exhibited changes in pain threshold of only $12.9 \%$ to 15.2\% (Figure 1B).

Thus, a single 10 min exposure of AP E-36 to P light caused a statistically significant increase in pain threshold in mice experiencing electrical stimulation of the skin on the foot, which suggests a decrease in sensitivity to pain.

Effects of $\mathrm{P}$ light on formalin-induced pain behaviour in mice Dependence on the area of action: Subcutaneous injection of the formalin solution into the left hind foot produced significant changes in mouse behaviour compared with the control injection of $\mathrm{NaCl}$ (Figure 2). Injection of formalin produced a $\mathrm{BR}$ to pain in the form of long, frequent periods of licking the painful area. In our first experiments (10), we supervised some mice $5 \mathrm{~h}$ after formalin injections and saw that the BR to pain lasted for several hours (sometimes lasting beyond the $5 \mathrm{~h}$ period of observation), but the most intense pain occurred during the first hour. It is known $(15,16)$ that the first hour after formalin injection in the hind foot of an animal has two phases: the early phase (acute pain, lasting approximately $5 \mathrm{~min}$ ) and late phase (tonic pain). In our experiments, the animals were placed in a chamber, limiting motor activity for $10 \mathrm{~min}$ after formalin injection, and the first phase (acute) of reaction to formalin administration could not be observed. As such, only the second phase (tonic) will be discussed.

Changes in BRs during a $1 \mathrm{~h}$ observation of the tonic phase of formalin-induced pain are shown in Figure 2A (this hour began after $10 \mathrm{~min}$ in the restraint cage). The mean duration of time that a mouse spent licking its foot within the first $10 \mathrm{~min}$ was $163.7 \pm 20.2 \mathrm{~s}$. In the subsequent $10 \mathrm{~min}$, the duration of licking reached a maximum of $196 \pm 22.8 \mathrm{~s}$ and then decreased slowly such that by the end of the $60 \mathrm{~min}$ it still exceeded $100 \mathrm{~s}$ $(116.4 \pm 32.7 \mathrm{~s})$. Injection of isotonic $0.9 \% \mathrm{NaCl}$ solution into the hind feet in the control group did not produce a significant BR to pain during the same time period.

Formalin-induced pain was decreased in the mice exposed to 10 min of P light on AP E-36. In the first 10 min of observation, the duration of licking was $70.2 \pm 21.7 \mathrm{~s}, 2.3$ times lower than that of the control group. The maximum duration of BR 
A

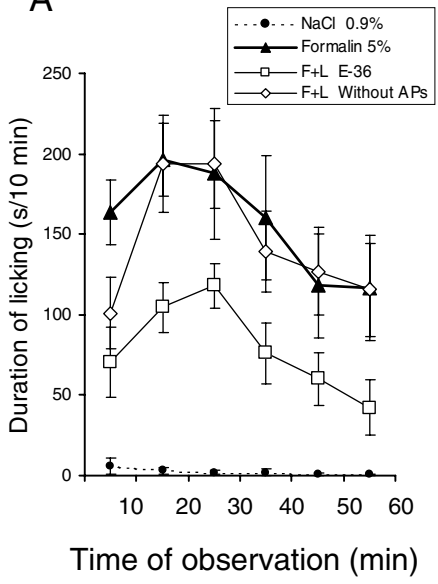

B

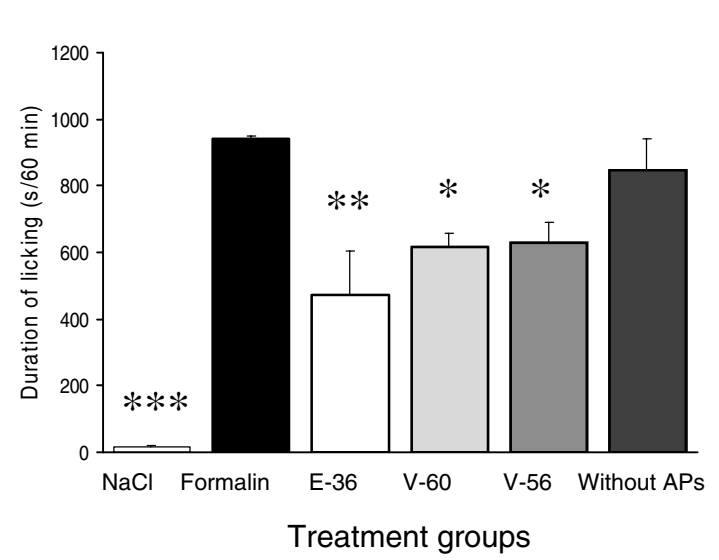

C

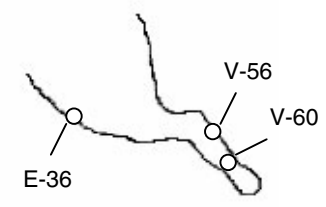

Lateral view

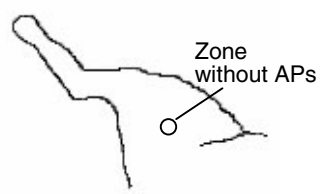

Medial view

Figure 2) The effect of polarized light on formalin-induced pain behaviour in mice. A Changes in formalin-induced nociceptive behavioural responses before and after exposure of acupuncture point (AP) E-36 or skin without any analgesic APs to polarized light. The mean ( \pm SEM) duration (s) of licking the painful area at 10 min intervals. B The mean ( \pm SEM) duration (s) of licking the painful area for a 60 min period of observation in six groups of mice that received: an injection of $0.9 \%$ sodium chloride $(\mathrm{NaCl})$ in the hind limb, an injection of $5 \%$ formalin (attenuated in $0.9 \% \mathrm{NaCl}$ ) in the hind limb, an injection of 5\% formalin in the hind limb followed by polarized light exposure of one AP (E-36, V-60 or V-56) or of skin without any analgesic APs. Significant difference from the control (formalin): *P<0.05, **P<0.01, ***P<0.001. C Localization of the zone exposed to polarized light. F+L Mice with formalin injection into the hind limb followed by P light therapy. Comparison with NaCl-evoked response

to pain for the experimental group occurred in the 20 min to 30 min interval of observation $(118.1 \pm 13.7 \mathrm{~s})$, which is 1.6 times lower than in the control group. After this, a decrease started immediately. During the last $10 \mathrm{~min}$ of observation, the duration of the BR to pain was $42.3 \pm 17.6 \mathrm{~s}, 2.8$ times less than the control group (Figure 2A). These differences were significant $(\mathrm{P}<0.01, \mathrm{P}<0.01$ and $\mathrm{P}<0.05$, respectively). Pain reduction was absent if the $\mathrm{P}$ light was directed at skin containing no specific analgesic APs (Figure 2A).

The effects of $\mathrm{P}$ light exposure were also studied on two other APs, V-60 and V-56. Results indicated that the antinociceptive effect depends substantially on choice of AP. Figure 2B shows a comparison of the mean duration in the BR $(60 \mathrm{~min}$ follow-up) in five groups of mice, four of which received a $P$ light session after formalin injection on one of the areas indicated in Figure 2C. Quantitative values of pain duration and other BRs for each group are summarized in Table 1 . The oneway ANOVA revealed significant differences in mean foot licking time among these groups $\left(\mathrm{F}_{4,45}=7.34, \mathrm{P}<0.001\right)$. If the licking time in the group of mice receiving only formalin injection (without P light treatment) is taken as $100 \%$ in the mice exposed to $\mathrm{P}$ light on AP E-36, the duration of pain reaction was one-half as large as in the group without any P light exposure $(\mathrm{P}<0.01)$. After exposure of APs V-60 and V-56 to P light, the duration of licking was reduced by 1.3 to 1.5 times $(\mathrm{P}<0.05)$. In the group where P light was directed at skin without specific analgesic APs, the duration of licking did not significantly differ from the control $(t=0.58)$.

Significant differences also occurred in the mean duration of nonpain behaviour in different groups of mice. The F-values $\left(\mathrm{F}_{4,45}\right)$ of the one-way ANOVA were 4.29 ( $\left.\mathrm{P}<0.01\right)$ for sleeping and $2.71(\mathrm{P}<0.05)$ for eating. The duration of sleeping in all groups with APs exposed to P light was significantly higher than that of the control group. The duration of eating, however, was significantly longer than that of the control for the group in which AP E-36 was exposed to P light. Other nonpain BRs (eg, running and washing) did not exhibit a clear dependence on the area of exposed to P light (Table 1).

Thus, the application of $\mathrm{P}$ light on APs reliably reduced the $\mathrm{BR}$ to pain and prolonged nonpain BRs. The same exposure of skin without any analgesic APs to P light did not produce statistically significant changes in the BR in mice with formalininduced pain. AP E-36 appeared to be the most effective AP of the three tested. Analgesia made up 50\% (E-36), 34.4\% (V-60) and $33.2 \%(\mathrm{~V}-56)$, respectively. We carried out comparative research of analgesic action of $\mathrm{P}$ and non-P light with other criteria remaining the same (data not published). It was discovered that non-P light did not produce any augmentation of pain threshold from the electrical stimulation of the feet and did not significantly change the duration of licking in the formalin test.

Dependence of P light effects on the duration of exposure: The dependence of $\mathrm{P}$ light effects on the duration of exposure of AP E-36 were also studied. The BR to pain induced by formalin injection, before and after P light exposure for $2 \mathrm{~min}, 6 \mathrm{~min}$ and $10 \mathrm{~min}$ in duration, is shown in Figure 3. One-way ANOVA revealed significant differences among these groups $\left(F_{3,36}=7.16, P<0.001\right)$. The greatest suppression of BR to pain was observed following a $10 \mathrm{~min}$ exposure to $\mathrm{P}$ light. If the duration of the BR to pain in the control group, over a $60 \mathrm{~min}$ period of observation, is taken as $100 \%$ then $2 \mathrm{~min}, 6 \mathrm{~min}$ and 10 min of exposure of AP E-36 to P light yielded licking durations of $92 \%, 69 \%$ and $50 \%$, respectively. Mean values for the duration of licking the painful area differed significantly from the control values for $6 \mathrm{~min}(t=2.13, \mathrm{P}<0.05)$ and $10 \mathrm{~min}$ $(t=3.45, \mathrm{P}<0.01)$ exposures to $\mathrm{P}$ light but not 2 min exposure $(t=0.49)$, as shown in Table 2 .

Two nonpain parameters were significantly different in P lighttreated mice compared with the control animals (Table 1). The one-way ANOVA revealed significant differences in the mean duration of sleeping $\left(\mathrm{F}_{3,36}=4.65, \mathrm{P}<0.01\right)$ and in the mean duration of eating $\left(\mathrm{F}_{3,36}=3.02, \mathrm{P}<0.05\right)$ between the 
TABLE 1

Duration (s/60 min of observation) of behavioural responses in mice with formalin-induced pain and different areas of polarized light exposure $(\mathrm{M} \pm \mathrm{m})$

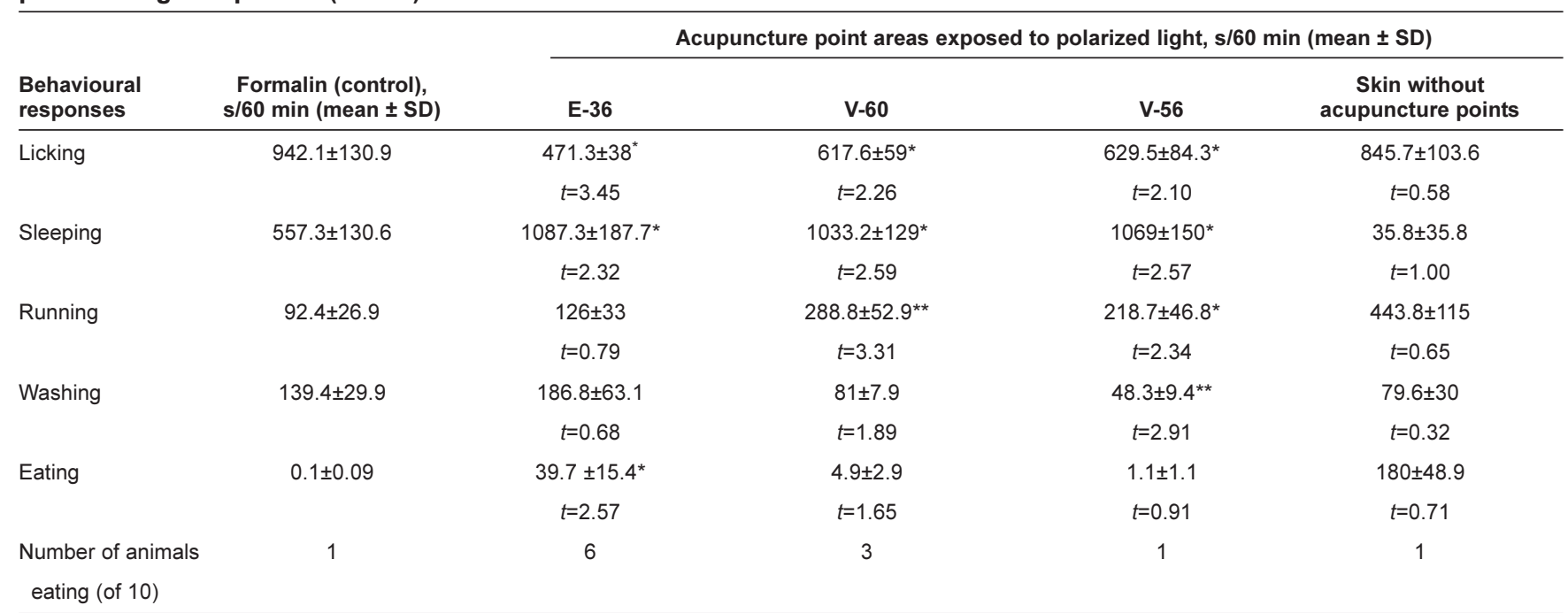

${ }^{*} P<0.05 ;{ }^{*} P<0.01$ compared with the control (otherwise not significant)
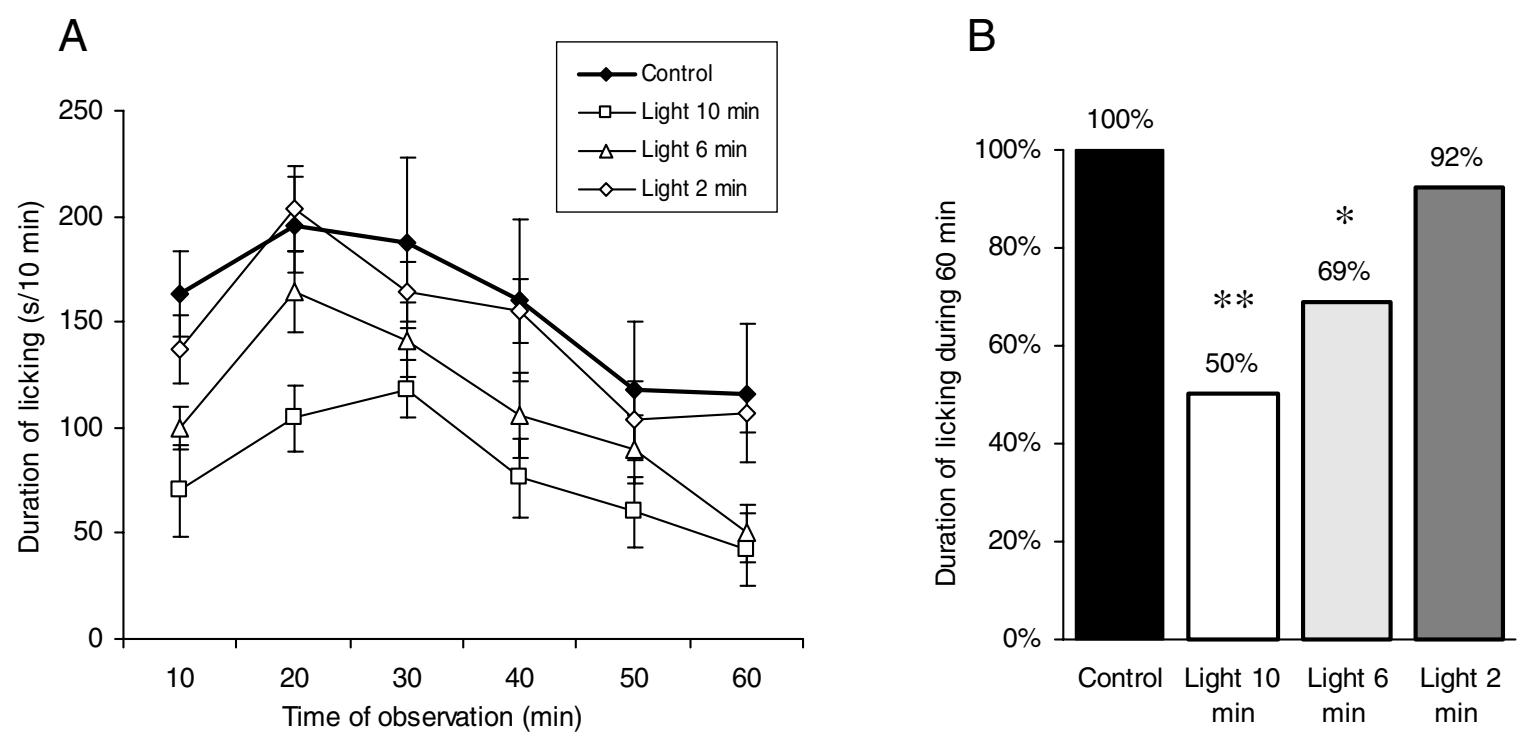

Figure 3) Dependence of the behavioural response to pain on exposure of acupuncture point (AP) E-36 to polarized light. A Mean ( \pm SEM) duration (s) of licking the painful area in sequential $10 \mathrm{~min}$ observation periods in control and after $2 \mathrm{~min}, 6 \mathrm{~min}$ or $10 \mathrm{~min}$ of exposure of AP E-36 to polarized light; B Mean duration of licking the painful area during the 60 min observation period (in \% of the control value) after different exposures to polarized light. Significant difference from the control: $* P<0.05, * * P<0.01$

groups. The time spent eating and sleeping differed significantly from the control $(\mathrm{P}<0.05)$ in the group with 10 min of $\mathrm{P}$ light exposure but not the 2 min or 6 min groups. There were no statistically significant differences among any groups in the nonpain BRs of running and washing.

Comparison of the P light effects on AP E-36 localized on the foot with and without the painful area: The changes in the duration of the BR to pain, observed in different groups of mice, are shown in Figure 4. In each animal, AP E-36 was exposed to $\mathrm{P}$ light (for $10 \mathrm{~min}$ ) just after formalin injection in the left foot. In one group, P light was applied on AP E-36 of the left foot, in the second on AP E-36 of the right foot and in the third, simultaneously on both AP E-36. The total duration of licking was $471.3 \pm 38.0 \mathrm{~s}, 459.5 \pm 70.3 \mathrm{~s}$ and $535.6 \pm 70.5 \mathrm{~s}$, respectively, against $942.1 \pm 130.9 \mathrm{~s}$ in the control group. The one-way ANOVA revealed significant differences in the mean licking time $\left(\mathrm{F}_{3,36}=5.68, \mathrm{P}<0.01\right)$ among groups. In all groups exposed to $\mathrm{P}$ light, the total licking time of the painful area, during a 60 min period of observation, reliably differed from that in the control group $(\mathrm{P}<0.01$ and $\mathrm{P}<0.05$, respectively) (Table 3). However, no significant differences were found among the three experimental groups. The total duration of the BR to pain in the three experimental groups differed by $50 \%, 49 \%$ and $57 \%$, respectively, from the control group (Figure 4B).

The one-way ANOVA also revealed significant differences among the groups in mean sleeping time $\left(\mathrm{F}_{3,36}=6.34, \mathrm{P}<0.01\right)$ and mean eating time $\left(\mathrm{F}_{3,36}=2.95, \mathrm{P}<0.05\right)$. P light exposure to the AP of one foot (either to the painful area or contralateral to the painful area) or simultaneously to APs of both feet 
TABLE 2

Duration (s/60 min of observation) of behavioural responses of mice with formalin-induced pain and different durations of exposure of acupuncture point (AP) E-36 to polarized light $(\mathrm{M} \pm \mathrm{m})$

\begin{tabular}{|c|c|c|c|c|}
\hline \multirow{2}{*}{$\begin{array}{l}\text { Behavioural } \\
\text { responses }\end{array}$} & \multirow{2}{*}{$\begin{array}{c}\text { Control, } \\
\text { s/60 min } \\
\text { (mean } \pm \text { SD) }\end{array}$} & \multicolumn{3}{|c|}{$\begin{array}{l}\text { Duration of exposure of AP E-36 to } \\
\text { polarized light, s/60 } \mathrm{min} \text { (mean } \pm \mathrm{SD} \text { ) }\end{array}$} \\
\hline & & $2 \mathrm{~min}$ & $6 \mathrm{~min}$ & $10 \mathrm{~min}$ \\
\hline \multirow[t]{2}{*}{ Licking } & $942.1 \pm 130.9$ & $870.2 \pm 64.3$ & $650.6 \pm 39.2^{*}$ & $471.3 \pm 38^{* \star}$ \\
\hline & & $t=0.49$ & $t=2.13$ & $t=3.45$ \\
\hline \multirow[t]{2}{*}{ Sleeping } & $557.3 \pm 130.6$ & $629.4 \pm 161.2$ & $869.4 \pm 176.5$ & $1087.3 \pm 187.7^{*}$ \\
\hline & & $t=0.35$ & $t=1.42$ & $t=2.32$ \\
\hline \multirow[t]{2}{*}{ Running } & $92.4 \pm 26.9$ & $154.5 \pm 35.6$ & $231.3 \pm 89.6$ & $126 \pm 33$ \\
\hline & & $t=1.39$ & $t=1.48$ & $t=0.79$ \\
\hline \multirow[t]{2}{*}{ Washing } & $139.4 \pm 29.9$ & $127.1 \pm 32.5$ & $165.4 \pm 32.7$ & $186.8 \pm 63.1$ \\
\hline & & $t=0.28$ & $t=0.59$ & $t=0.68$ \\
\hline \multirow[t]{2}{*}{ Eating } & $0.1 \pm 0.09$ & 0 & $27.5 \pm 19.1$ & $39.7 \pm 15.4^{*}$ \\
\hline & & & $t=1.43$ & $t=2.57$ \\
\hline \multicolumn{2}{|c|}{$\begin{array}{l}\text { Number of animals } \\
\text { eating (of 10) }\end{array}$} & 0 & 2 & 6 \\
\hline
\end{tabular}

${ }^{*} P<0.05 ;{ }^{* *} P<0.01$ compared with control (otherwise not significant)

caused an increased duration in sleeping and eating (Table 3), which also indicates pain relief.

The data obtained show that the effect of P light does not depend on whether the AP E-36 is located on the same extremity as the painful area or contralateral to the painful area. Simultaneous illumination of both APs did not increase the antinociceptive effect.

The ratio between pain and nonpain responses in mice before and after application of $\mathrm{P}$ light: The experimental data represented show that exposure of APs to P light results in decreased licking of the formalin-injected painful area, and increased duration of nonpain BRs (eg, sleeping and eating). Thus, pain intensity can be described by the ratio of pain and nonpain reactions before and after $\mathrm{P}$ light application. The behaviour of mice under normal conditions, after formalin injection, and after formalin injection followed by a $10 \mathrm{~min}$ session of P light on AP E-36, is illustrated in Figure 5.

If the time necessary for all observed behaviour is assumed to be $100 \%$ (full circle) changes in the ratio between pain and nonpain reactions among different groups will be evident. Under normal conditions (without any influences), the mice were eating or sleeping $75 \%$ of the time (eating $36 \%$ and sleeping $39 \%$ ) and running or washing $25 \%$ of the time. In the group of animals that received formalin injection but no P light treatment, we could see decreased sleeping and complete absence of eating (none of 10 mice touched the feed). For more than one-half of the time (55\%), these animals licked their painful feet. In the group that received the formalin injection followed by a 10 min exposure of AP E-36 to P light, the total licking time of the painful area reliably differed from that in the group without $\mathrm{P}$ light treatment $(\mathrm{P}<0.01)$, licking time decreased by 2.2 times (suggesting pain relief). The duration of sleeping increased by 1.8 times; the difference between this group and the group without $\mathrm{P}$ light treatment was significant $(\mathrm{P}<0.05)$. Some of the mice (six of 10$)$ ate the feed for a short period of time. However, no significant differences were found between these two groups in BRs such as washing and running.

\section{DISCUSSION}

Interest in nonpharmacological treatment of different diseases, particularly acupuncture therapy for pain, is growing. One acupuncture method is a direct action of low-intensity EMFs on APs. As clinical practice has shown, the advantage of EMFs (eg, microwaves, visible light, infrared rays and magnetic fields) over other acupuncture methods (eg, introduction of metallic needles into APs, cauterization or refrigeration of APs, electropuncture or electroacupuncture) is the ability of EMFs to render medical care without contacting the patients' body or producing painful sensations. The experimental data discussed here clearly show that low-intensity P light, when
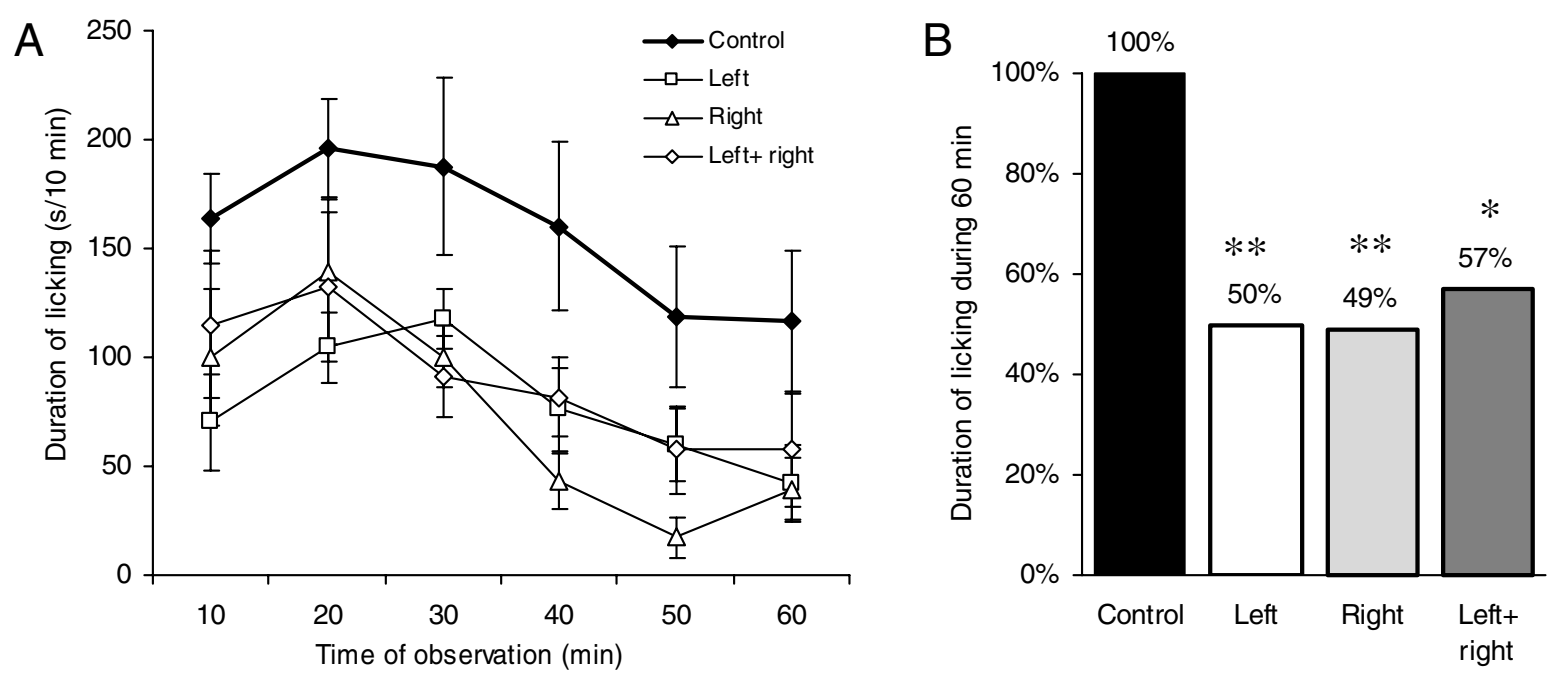

Figure 4) The duration of licking the painful area after exposure of acupuncture point (AP) E-36 on the left foot, right foot or both feet to polarized light. A Mean ( \pm SEM) duration (s) of licking the painful area in sequential 10 min observation periods for the control group (no light exposure) and three experimental groups (10 min exposure to polarized light of AP E-36 located on the left foot, right foot or both feet); B Mean ( \pm SEM) duration (s) of licking the painful area for $60 \mathrm{~min}$ of observation (\% of the control value) in the same groups as in A. Significant difference from the control: $* P<0.05, * * P<0.01$ 
applied on APs, may significantly suppress both acute and tonic pain. The literature contains no information on application of $\mathrm{P}$ light for the suppression of pain. The action of $\mathrm{P}$ light on APs can, to some extent, be compared with the radiation effect of low-intensity lasers. P light differs from laser radiation by its polychromatism and noncoherence.

\section{The effect of $\mathrm{P}$ light on acute pain}

The model of mouse vocalization on an electrode floor was used to study acute pain. The vocalization reaction is known to involve participation of the supraspinal structures in the brain (18). Data in the literature show an increase in the threshold of vocalization caused by electrical stimuli after exposure of APs to electrical current (electroacupuncture) (19), lowintensity laser radiation (20) or low-intensity microwaves (10). The literature completely lacks information about the effects of P light on the intensity of acute pain.

The results given here show that a single 10 min exposure of the analgesic AP E-36 on a mouse to P light caused a statistically significant increase in pain threshold upon electrical stimulation on the skin of the foot. Such an antinociceptive effect lasted more than $3 \mathrm{~h}$ and had a magnitude of $34.2 \%$ to $59.1 \%$.

Each animal was used once, which decreased the possibility of forming a habit. No substantial conclusion could be made about the mices' learning behaviour as a result of the experiment. Controlled experiments showed that during $4 \mathrm{~h}$, the pain threshold on electric stimulation of foot skin was changed in limits between $12.9 \%$ to $15.2 \%$.

All mice (experimental and control) received equal restraint. The mice in the control group, however, showed no significant increase in their pain threshold after restraint. A statistically significant increase in pain threshold occurred only in the group of mice that had an AP exposed to P light. We concluded that the restraint used did not have a significant effect and thus, that the analgesia results from the action of P light on APs.

These results are consistent with the data obtained from studying laser (monochromatic P light) effects on pain in humans. It was shown (21) that exposure of triggering (starting) points with infrared laser energy in patients with pain syndromes increased their pain thresholds considerably. The largest increases were caused by exposure of APs located on the meridians (22). In a study of acupuncture's influence on the somatosensory potentials caused by pain stimuli in animals and humans, a decrease in potential amplitude, increase in the appearance of the latency period and an increase in threshold sensitivity to pain were found (23).

The effect of $\mathrm{P}$ light on formalin-induced pain behaviour In animals with areas of tonic pain, exposure of specific analgesic APs to P light significantly depressed the BR to pain (licking of the painful area). P light also reduced the total duration of the BR to pain ( $50 \%$ of the duration as seen in the control). The duration of nonpain BRs (eg, sleeping and eating) was simultaneously prolonged. These effects are due to P light exposure and are not a form of restraint analgesia, because all mice (experimental and control) received equal restraint.

In our experiments, the power of $\mathrm{P}$ light was a constant value $\left(40 \mathrm{~mW} / \mathrm{cm}^{2}\right)$, and the amount of EMF energy acting through APs on the organism was determined only by time. The antinociceptive effect of P light depends mainly on duration of its action on APs. After $2 \mathrm{~min}, 6 \mathrm{~min}$ and $10 \mathrm{~min}$ of
TABLE 3

Duration (s/60 min of observation) of behavioural responses in mice with formalin-induced pain before and after $10 \mathrm{~min}$ of polarized light exposure to acupuncture point E-36 of the left foot, right foot and both feet simultaneously ( $\mathrm{M} \pm \mathrm{m}$ )

\begin{tabular}{lcccc}
\hline & & \multicolumn{3}{c}{$\begin{array}{c}\text { Cocation exposed to polarized light, } \\
\text { S/60 } \mathbf{m i n}(\text { mean } \pm \text { SD) }\end{array}$} \\
\cline { 3 - 5 } $\begin{array}{l}\text { Behavioural } \\
\text { responses }\end{array}$ & $\begin{array}{c}\text { s/60 } \mathbf{m i n} \\
\text { (mean } \pm \text { SD) }\end{array}$ & $\begin{array}{c}\text { Left hind } \\
\text { limb }\end{array}$ & $\begin{array}{c}\text { Right hind } \\
\text { limb }\end{array}$ & $\begin{array}{c}\text { Left and right } \\
\text { hind limbs }\end{array}$ \\
\hline Licking & $942.1 \pm 130.9$ & $471.3 \pm 38.0^{* *}$ & $459.5 \pm 70.3^{* *}$ & $535.6 \pm 70.5^{*}$ \\
& & $t=3.45$ & $t=3.23$ & $t=2.73$ \\
Sleeping & $557.3 \pm 130.6$ & $1087.3 \pm 187.7^{*}$ & $1560 \pm 124.3^{* * *}$ & $1147.0 \pm 168.5^{*}$ \\
& & $t=2.32$ & $t=5.56$ & $t=2.77$ \\
Eating & $0.1 \pm 0.09$ & $39.7 \pm 15.4^{*}$ & $5.8 \pm 5.8$ & $126.7 \pm 71.6$ \\
& & $t=2.57$ & $t=0.98$ & $t=1.77$ \\
Number of animals 1 & 6 & 1 & 6 \\
eating (of 10) & & & & \\
\hline
\end{tabular}

${ }^{*} P<0.05 ;{ }^{* *} P<0.01 ;{ }^{* \star} P<0.001$ compared with control (otherwise not significant)

exposure to $\mathrm{P}$ light, analgesia was $7.6 \%, 30.9 \%$ and $50 \%$, respectively. Analgesia after $10 \mathrm{~min}$ of AP exposure to P light was almost equal to that obtained with the sedative method of classic acupuncture (15), which requires prolonged exposure to needles.

Research on the antinociceptive action of low-intensity laser EMFs on APs $(20,24-27)$ has shown that the therapeutic effect is produced via the opioidergic systems of the brain stem and is accompanied by depression of the late (nociceptive) components of somatosensory evoked potentials. During analgesia, caused by exposure of APs to low-intensity laser light, ATP and serotonin synthesis increased in cells and a reduction in the inflammatory process was observed (28).

Others have shown (29) that specific properties of electro puncture stimulation of AP E-36 in rats produces a two-component (brief and prolonged) suppression of the tail flick reflex, which is considered demonstrative of analgesia. The appearance of analgesia depends on stimulation parameters (eg, frequency and voltage) and duration. The prolonged components of electropuncture analgesia, which remain for approximately $1 \mathrm{~h}$, depend on the plastic changes in the spinal and supraspinal centres (29). The suppression of nociceptive reflexes caused by electroacupuncture is achieved due to increased production of opioid peptides, amines, hormones and other compounds (14), and activation of different types of opioid receptors (30).

As our experiments have shown, the BR to pain was significantly reduced only when APs were exposed to P light. The same exposure of skin without APs to P light did not induce a statistically significant lowering of the duration of the BR to pain. These data confirm a specificity of APs, which, on their morphological, electrical and other characteristics, differ from surrounding skin. Thus, APs and non-APs have different connections and pathways in the central nervous system (31). APs absorb greater amounts of radioactive isotopes and do so faster than adjacent regions of the skin (32). After electro puncture of the APs lying in the meridians, obvious antinociceptive effects arose (22). Considerable changes in nociceptive evoked potentials were observed in human brains after AP GI-4 stimulation, but such changes did not appear if the adjacent nonacupuncture area was stimulated (33). 


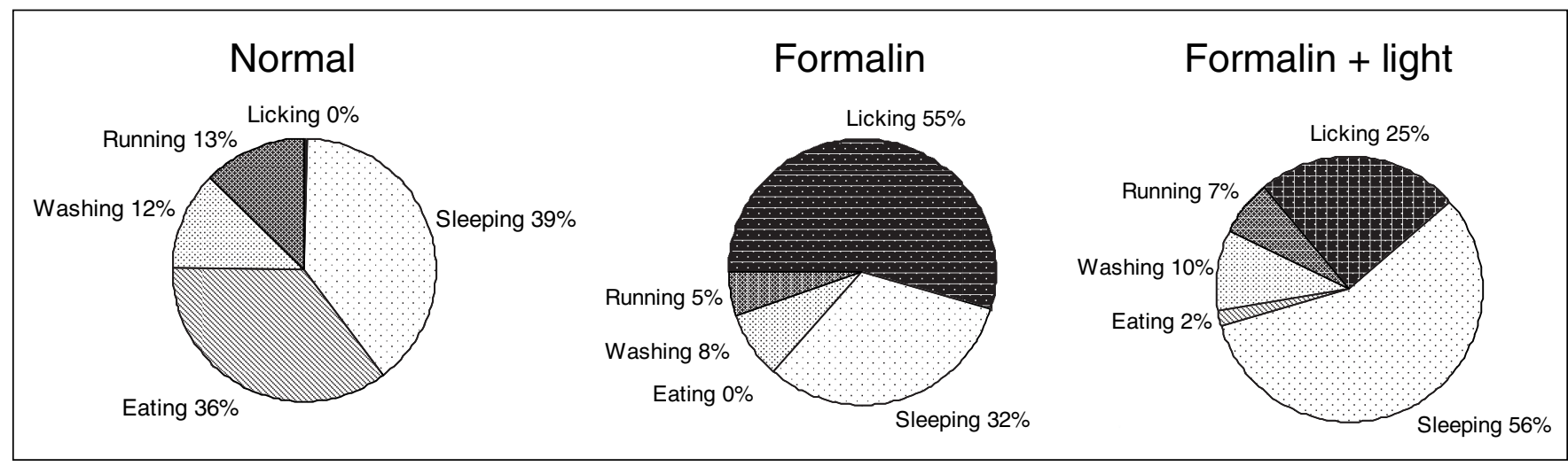

Figure 5) Comparison of behavioural responses in normal, formalin-tested and formalin-tested mice that had acupuncture point E-36 exposed to polarized light (10 $\mathrm{min})$. Area of a whole circle was taken as 100\%

Introduction of the acupuncture needle into the human AP E-36 produced specific changes in the spectrum of the radial arterial pulse, but such changes did not occur if the needle was introduced into the skin outside the AP (34). The injection of apitoxin into AP E-36 of rats suffering from chronic arthritis evoked a considerably more pronounced antinociceptive and anti-inflammatory effect than the same injection into the skin outside the AP (35).

The antinociceptive efficacy of $\mathrm{P}$ light has been studied for three APs widely used in the practice of acupuncture to relieve pain: E-36, V-60 and V-56. Only AP E-36 and V-60 yield statistically significant analgesia $(50 \%$ and $34.4 \%$, respectively). It was shown that the more effective point to relieve pain localized on the back of the foot of the mouse hind limb was AP E-36. These facts are consistent with the data obtained in a clinical trial by Stasinopoulos et al (36). AP E-36 is one of the most effective points in traditional Chinese medicine. It is innervated through a common tibial nerve from the L IV to L V segments of the spinal cord (37); the same segments innervate the back of foot in humans and rodents $(38,39)$. Obviously, the depth of analgesia also depends on segmental innervations. This agrees with the observations of other authors (40) who established dependence of the depth of analgesia on specific properties of APs or their innervations.

The decrease in BR to pain in our experiments was elicited by exposure of AP E-36 to P light not only on the foot with the painful area, but also on AP E-36 of the contralateral foot. The antinociceptive effects were approximately identical (50\% and 51.2\%, respectively). Simultaneous application of P light on both APs E-36 yielded no intensification of analgesia. Similar results were obtained with electroacupuncture

\section{REFERENCES}

1. Stelian J, Gil I, Habot B, et al. Improvement of pain and disability in elderly patients with degenerative osteoarthritis of the knee treated with narrow-band light therapy. J Am Geriatr Soc 1992;40:23-6.

2. Mokhtar B, Baxter GD, Walsh DM, Bell AJ, Allen JM. Doubleblind, placebo-controlled investigation of the effect of combined phototherapy/low intensity laser therapy upon experimental ischaemic pain in humans. Lasers Surg Med 1995;17:74-81.

3. Gupta G, Long J, Tillman DM. The efficacy of narrowband ultraviolet B phototherapy in psoriasis using objective and subjective outcome measures. Br J Dermatol 1999;140:887-90.

4. Craig JA, Barron J, Walsh DM, Baxter GD. Lack of effect of combined low intensity laser therapy/phototherapy (CLILT) on both in experiments on animals and in clinical studies of humans $(41,42)$. It is possible to suggest that ipsi- and contralateral APs E-36 activate the same levels of the brain antinociceptive systems. According to some authors $(41,42)$, such levels are three to four layers of the spinal cord, the lateral paragigantocellular nucleus of the medulla and the dorsal region of midbrain central gray matter.

Looking at Figure 5 and Tables 1, 2 and 3, yet another effect of P light exposure seems apparent. Despite still showing signs of pain (licking), these mice also, counterintuitively, show increased sleeping. This may be because, in addition to reducing pain, it is known that AP E-36 and some other APs produce a simultaneous release of enkephalin, betaendorphin, endomorphin and dynorphin, the peptides that play an essential role in mediating the analgesic effect of acupuncture (43). Acupuncture also increases nocturnal melatonin secretion and reduces insomnia and anxiety in people (44), and has an anxiolytic effect at the rats who have undergone restraint-induced stress (45). In time, most people notice that they sleep longer and that their quality of sleep improves after AP stimulation $(46,47)$. All this indicates that sleep in animals under action of P light on APs, where analgesic action is combined with removal of a strain, feelings of fear and excitation, may differ on a number of mechanisms from physiological sleep.

This method exerts less intensive influence on APs than classic acupuncture, but it is no less effective on the curative effect. In addition, $\mathrm{P}$ light does not damage skin, which excludes an opportunity for infection by various viral diseases transmitted through blood. Treatment with P light is accessible for domestic applications, for therapy of weakened patients, the elderly and children. delayed onset muscle soreness in humans. Lasers Surg Med 1999;24:223-30. (Erratum in 1999;25:88).

5. Westerdahl J, Olsson H, Masback A, et al. Use of sunbeds or sunlamps and malignant melanoma in southern Sweden. Am J Epidemiol 1994;140:691-9.

6. Jansen C. [Effect of sunlight on skin - what have we learned?] Nord Med 1995;110:85-7.

7. Stender IM, Andersen JL, Wulf HC. Sun exposure and sunscreen use among sunbathers in Denmark. Acta Derm Venereol 1996;76:31-3.

8. Zanetti R, Rosso S, Martinez C, et al. The multicentre south European study 'Helios'. I: Skin characteristics and sunburns in basal cell and squamous cell carcinomas of the skin. Br J Cancer 1996;73:1440-6. 
9. Limanskii luP. [The hypothesis of acupuncture points as polymodal receptors of the ecoceptive sensitivity system.] Fiziol Zh 1990;36:115-21.

10. Limanskii IuP, Tamarova ZA, Bidkov EG, Kolbun ND. Suppression of animal's nociceptive reactions by action of low intensive microwaves onto acupuncture point. Neurophysiology 1999;31:290-4.

11. Schoen AM, ed. Veterinary Acupuncture: Ancient Art to Modern Medicine, 2nd edn. St Louis: Mosby, 2001.

12. Shankar N, Varshney A, Bhattacharya A, Sharma KN. Electroacupuncture, morphine and clonidine: A comparative study of analgesic effects. Indian J Physiol Pharmacol 1996; $40: 225-30$

13. Cao Q, Liu J, Chen S, Han Z. Effects of electroacupuncture at neiguan on myocardial microcirculation in rabbits with acute myocardial ischemia. J Tradit Chin Med 1998;18:134-9.

14. Luvsan G. Sketches of East Reflexotherapy Methods. Novosibirsk: Science, 1991.

15. Han SH, Yoon SH, Cho YW, Kim CJ, Min BI. Inhibitory effects of electroacupuncture on stress responses evoked by tooth-pulp stimulation in rats. Physiol Behav 1999;66:217-22.

16. Dubuisson D, Dennis SG. The formalin test: A quantitative study of the analgesic effects of morphine, meperidine, and brain stem stimulation in rats and cats. Pain 1977:4:161-74.

17. Hunskaar S, Fasmer OB, Hole K. Formalin test in mice, a useful technique for evaluating mild analgesics. J Neurosci Methods 1985;14:69-76.

18. Christensen MD, Hulsebosch E. Chronic central pain after spinal cord injury. J Neurotrauma 1997;14:517-37.

19. Zhao F, Zhu L, Li Y. [Therapeutic effects of electroacupuncture (EA) on acute experimental arthritis in rats.] Zhen Ci Yan Jiu 1990;15:197-202.

20. Zhu L, Li C, Ji C, Li W. [The effect of laser irradiation on arthritis in rats.] Zhen Ci Yan Jiu 1990;15:71-6.

21. Olavi A, Pekka R, Pertti K, Pekka P. Effects of the infrared laser therapy at treated and non-treated trigger points. Acupunct Electrother Res 1989;14:9-14.

22. Farber PL, Tachibana A, Campiglia HM. Increased pain threshold following electroacupuncture: Analgesia is induced mainly in meridian acupuncture points. Acupunct Electrother Res 1997;22:109-17.

23. Xu Y. Treatment of acute pain with auricular pellet pressure on ear shenmen as the main point. J Tradit Chin Med 1992;12:114-5.

24. Kreczi T, Klingler D. A comparison of laser acupuncture versus placebo in radicular and pseudoradicular pain syndromes as recorded by subjective responses of patients. Acupunct Electrother Res 1986;11:207-16.

25. Bian XP, Yu ZQ, Liu DM. [The experiment studies of semiconductor GaAs-laser points irradiation the analgesic effect.] Zhen Ci Yan Jiu 1989;14:379-82.

26. Milchev N, Krutov G, Piperkov T. [The use of low-energy lasers via action on the acupuncture points in inflammatory processes in the adnexa.] Akush Ginekol (Sofia) 1992;31:25-7.

27. Sing T, Yang MM. Electroacupuncture and laser stimulation treatment: Evaluated by somatosensory evoked potential in conscious rabbits. Am J Chin Med 1997;25:263-71.

28. Branco K, Naeser MA. Carpal tunnel syndrome: Clinical outcome after low-level laser acupuncture, microamps transcutaneous electrical nerve stimulation, and other alternative therapies - an open protocol study. J Altern Complement Med 1999;5:5-26.
29. Romita VV, Suk A, Henry JL. Parametric studies on electroacupuncture-like stimulation in a rat model: Effects of intensity, frequency, and duration of stimulation on evoked antinociception. Brain Res Bull 1997;42:289-96.

30. Chen XH, Han JS. Analgesia induced by electroacupuncture of different frequencies is mediated by different types of opioid receptors: Another cross-tolerance study. Behav Brain Res 1992;47:143-9.

31. Takeshige C. Differentiation between acupuncture and nonacupuncture points by association with analgesia inhibitory system. Acupunct Electrother Res 1985;10:195-202.

32. Chen MF, Wu CC, Jong SB, Lin CC. Differences in acupuncture point SP-10 and non-acupuncture point following subcutaneous injection of Tc-99m pertechnetate. Am J Chin Med 1993;21:221-9.

33. Abad-Alegria F, Adelantado S, Martinez T. The role of the cerebral cortex in acupuncture modulation of the somesthetic afferent. Am J Chin Med 1995;23:11-4.

34. Wang WK, Hsu TL, Chang HC, Wang YY. Effect of acupuncture at Tsu San Li (St-36) on the pulse spectrum. Am J Chin Med 1995;23:121-30.

35. Kwon YB, Lee JD, Lee HL, et al. Bee venom injection into an acupuncture point reduces arthritis associated edema and nociceptive responses. Pain 2001;90:271-80.

36. Stasinopoulos D, Stasinopoulos I, Johnson MI. Treatment of carpal tunnel syndrome with polarized polychromatic noncoherent light (Bioptron light): A preliminary, prospective, open clinical trial. Photomed Laser Surg 2005;23:225-8.

37. Xu R, Guo D, Qin H, Guan X. [Electroacupuncture along meridians activating subcutaneous primary afferents in acupoints - CB-HRP tracing study.] Zhen Ci Yan Jiu 1996;21:54-8.

38. Bossy J. [Neurobiological bases of reflexotherapies - Monographs of applied reflexotherapy.] Paris: Masson, 1978.

39. Yang J, Tang J, Yuan B, Jia H. [Responses of neurons in thalamic nucleus submedius to electrical stimulation of peroneal nerve and "zusanli" point in rats.] Zhen Ci Yan Jiu 1996;21:28-33.

40. Liu X, Zhang S, Wei B. [The relation of the relative specificity of point to channel lines or spinal segments.] Zhen Ci Yan Jiu 1995;20:54-9.

41. Ji RR, Zhang Q, Han JS. [Electroacupuncture enhances enkephalin mRNA expression in the spinal cord and medulla, an in situ hybridization study.] Sheng Li Xue Bao 1993;45:395-9.

42. Fang JQ, Liu YL, Mo XM. [Clinical and experimental studies on analgesic effects of ipsilateral and contralateral stimulations with electroacupuncture.] Zhongguo Zhong Xi Yi Jie He Za Zhi 1994;14:579-82.

43. Han JS. Acupuncture and endorphins. Neurosci Lett 2004;361:258-61.

44. Spence DW, Kayumov L, Chen A, et al. Acupuncture increases nocturnal melatonin secretion and reduces insomnia and anxiety: A preliminary report. J Neuropsychiatry Clin Neurosci 2004;16:19-28.

45. Guimaraes CM, Pinge MC, Yamamura Y, Mello LE. Effects of acupuncture on behavioral, cardiovascular and hormonal responses in restraint-stressed Wistar rats. Braz J Med Biol Res 1997;30:1445-50.

46. Carlsson CP, Sjolund BH. Acupuncture for chronic low back pain A randomized placebo-controlled study with long-term follow-up. Clin J Pain 2001;17:296-305.

47. Stux G, Hammerschlag R, eds. Clinical Acupuncture: Scientific Basis. Berlin: Springer, 2001. 


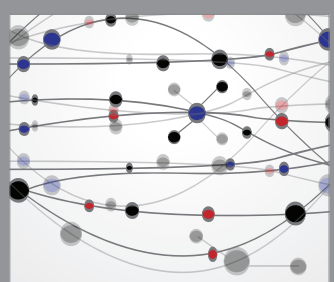

The Scientific World Journal
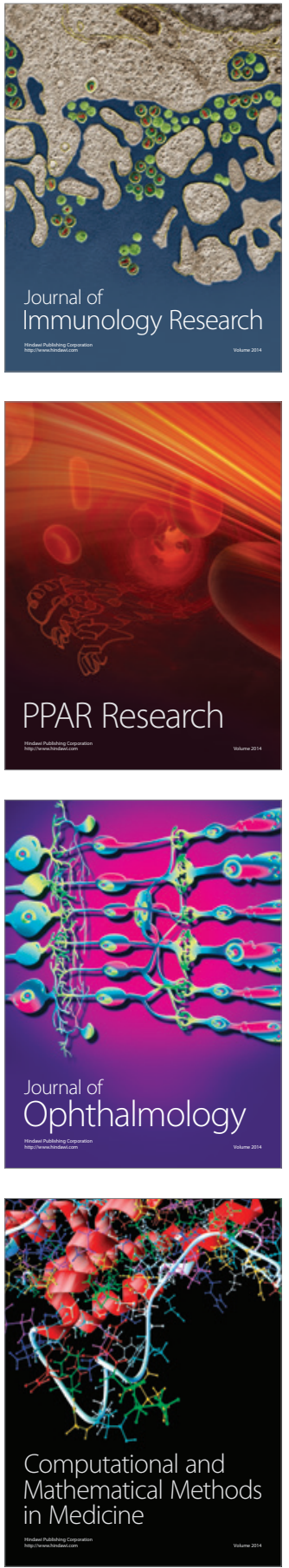

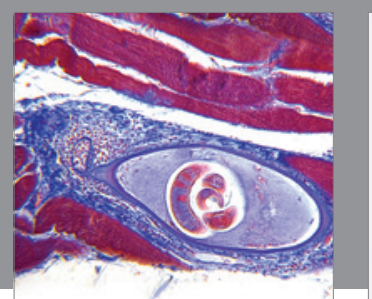

Gastroenterology Research and Practice

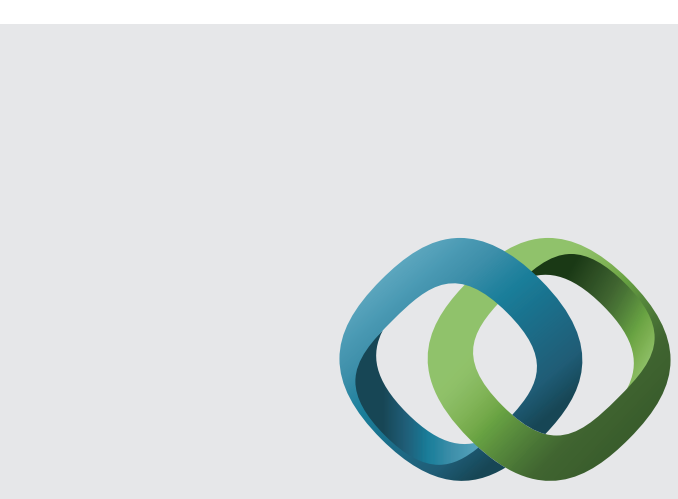

\section{Hindawi}

Submit your manuscripts at

http://www.hindawi.com
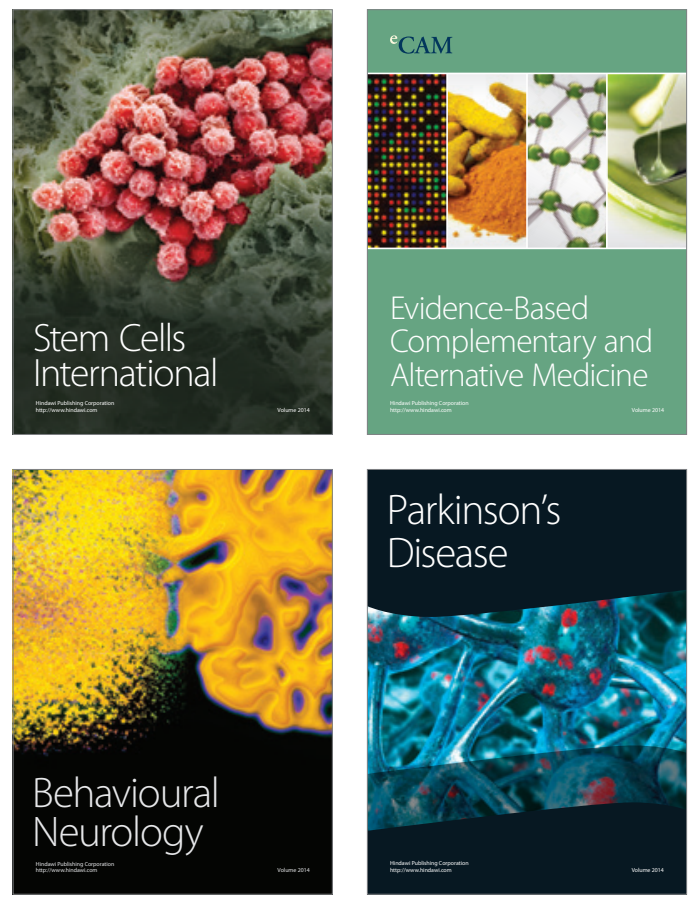
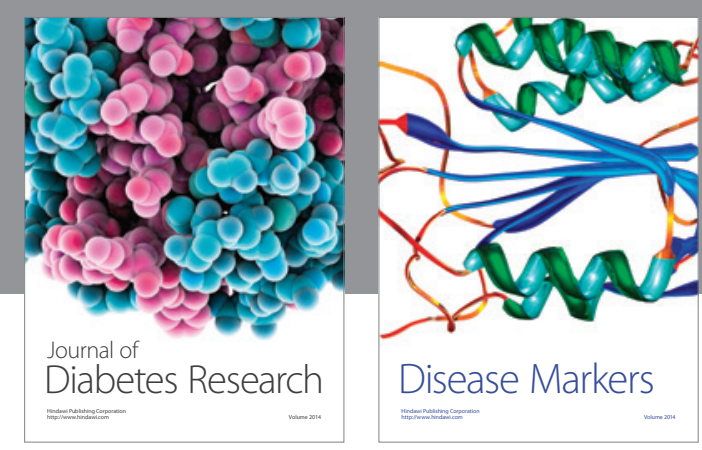

Disease Markers
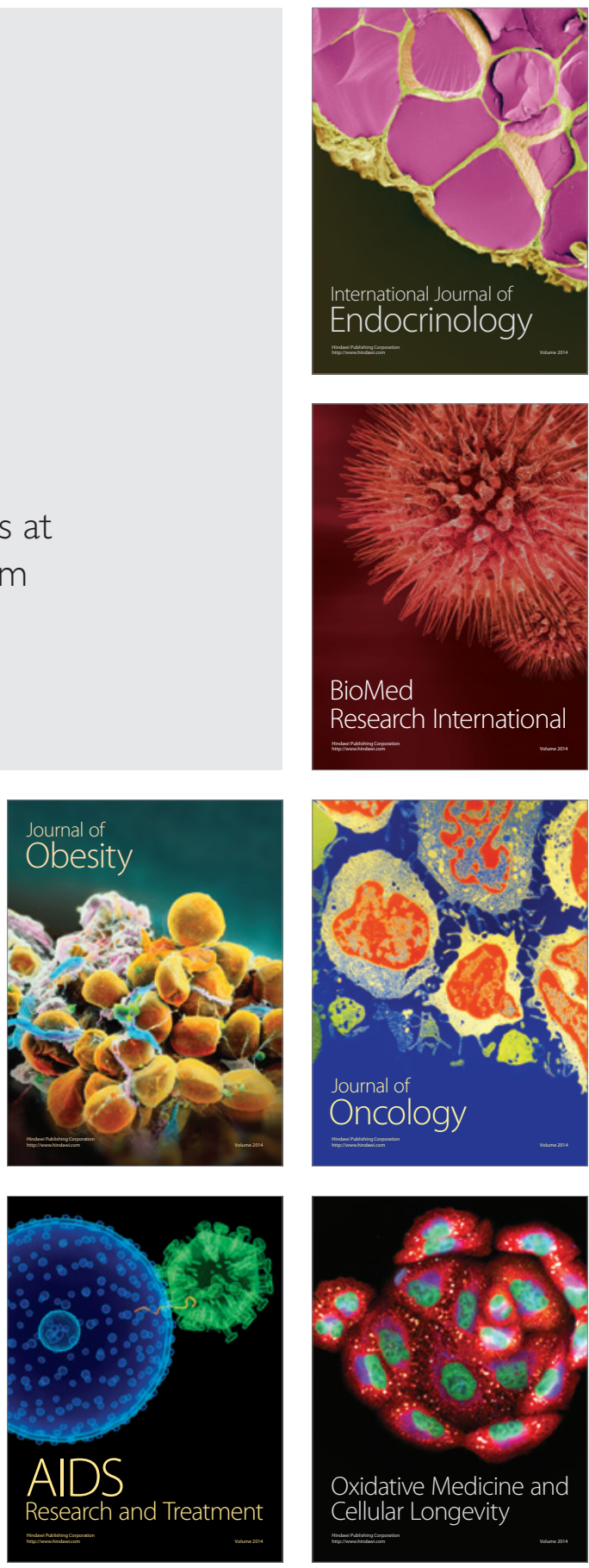